\title{
Combination of ICSs and LABAs should be used in the management of patients with COPD - The pro argument
}

\author{
Don D Sin MD
}

\section{THE EFFECTS OF INHALED \\ CORTICOSTEROID MONOTHERAPY}

Airway inflammation is a prominent feature of chronic obstructive pulmonary disease (COPD), even among ex-smokers (1), and its intensity is directly related to the severity of the underlying COPD (2). The inflammatory burden increases during periods of clinical exacerbation (3-5). Predictably, use of systemic corticosteroids during these episodes accelerates clinical recovery and improves health outcomes over several months of follow-up (6). Unfortunately, long term use of systemic corticosteroids is generally precluded by their toxic side effects. Inhaled corticosteroids, on the other hand, share much of the anti-inflammatory properties of the systemic formulations without the side effects (7). However, their effectiveness has been questioned and is a matter of heated debate among members of the scientific community $(8,9)$.

Some have argued that the inflammatory process in the COPD airways may be resistant to corticosteroids for various reasons. First, cells within COPD airways have reduced histone deacetylase activity (10). Histone deacetylase is an important cofactor that assists corticosteroids in deactivating various inflammatory genes; its deficiency may, therefore, make the inflammatory process more resistant to the effects of corticosteroids (10). Second, corticosteroids have minimal effects on neutrophils, which are found in abundance in the airway lumen of COPD patients and are thought to have some (if not a predominant) role in COPD pathogenesis (10). Indeed, in some cases, corticosteroids may delay neutrophil apoptosis, which, paradoxically, could promote airway neutrophilia.

Notwithstanding these theoretical concerns, clinical studies have demonstrated that inhaled corticosteroids can downregulate certain components of the inflammatory process within COPD airways. Patel and coworkers (11), for example, showed a marked attenuation of interleukin (IL)- 6 and IL-8 production by bronchial epithelial cells from COPD patients taking inhaled corticosteroids compared with COPD patients not taking inhaled corticosteroids. In another experiment, six weeks of inhaled beclomethasone $(1.5 \mathrm{mg} /$ day $)$ reduced IL-8 levels by $68 \%$ in the bronchial lavage fluid of patients with mild to moderate COPD (12). IL-8 is important in neutrophil recruitment and chemotaxis. This may explain why, although corticosteroids have minimal direct effects on neutrophils, Confalonieri and coworkers (13) demonstrated a marked reduction in the number of neutrophils in the sputum of
COPD patients after eight weeks of treatment with inhaled beclomethasone (1.5 mg/day).

Inhaled corticosteroids have other anti-inflammatory properties. They reduce the expression of soluble intercellular adhesion molecules, which are important molecules in effecting transmigration of proinflammatory cells across the endothelial surface into deeper tissues (11). They also repress mast cell expression in the stromal layers of bronchial epithelium. For example, three months of inhaled fluticasone therapy reduce the subepithelial mast cell concentration by $24 \%$ (14). Furthermore, four weeks of inhaled beclomethasone can reduce sputum eosinophil numbers by $47 \%$ (from baseline) (12). They also reduce inducible nitric oxide synthase-positive and nitrotyrosine-positive cells by $40 \%$ and $39 \%$, respectively, from baseline levels, suggesting that, in addition to their antiinflammatory effects, inhaled corticosteroids may attenuate oxidative stress within COPD airways (15).

Not surprisingly, given these biological effects of inhaled corticosteroids on the inflammatory and oxidative processes in the airways of COPD, large, randomized, controlled trials have demonstrated that inhaled corticosteroids have salutary effects on clinically relevant health outcomes. A meta-analysis of data from large, randomized studies showed that inhaled corticosteroids reduce clinical exacerbation rates by approximately $25 \%$ relative to placebo among COPD patients (relative risk [RR] 0.76; $95 \%$ CI 0.72 to 0.80$)(16,17)$. The magnitude of the risk reduction was similar between short (less than one-year) and long (four-year) trials, suggesting that the symptomatic benefit of inhaled corticosteroids extends to at least three to four years of follow-up (16). The beneficial effects were more pronounced among those with severe underlying disease (forced expiratory volume in $1 \mathrm{~s}\left[\mathrm{FEV}_{1}\right]$ less than $50 \%$ predicted). They were not particularly beneficial among those with an $\mathrm{FEV}_{1}$ greater than $2.0 \mathrm{~L}$ (17). Inhaled corticosteroids also reduced the rate of decline in health status in COPD. For the Symptoms component of the St George's Respiratory Questionnaire, inhaled corticosteroids decelerated the rate of deterioration by over $50 \%$ (18). In other areas of the St George's Respiratory Questionnaire (Activity and Impacts score), the rate of deterioration was attenuated by approximately one-third compared with placebo, which represented clinically relevant changes (18). Discontinuation of inhaled corticosteroids, on the other hand, resulted in an increase in patient symptoms and an elevated risk of exacerbations. Van der Valk and colleagues (19) demonstrated among 244 COPD patients (with a mean $\mathrm{FEV}_{1}$ of approximately $1.7 \mathrm{~L}$ )

James Hogg iCapture Centre for Cardiovascular and Pulmonary Research; Department of Medicine, Pulmonary Division, University of British Columbia, Vancouver, British Columbia; Institute of Health Economics, Edmonton, Alberta

Correspondence: Dr Don D Sin, James Hogg iCAPTURE Center for Cardiovascular and Pulmonary Research, St Paul's Hospital, Room 368A, 1081 Burrard Street, Vancouver, British Columbia V5Z 1Y7. Telephone 604-806-8395, fax 604-806-9274, e-mail dsin@mrl.ubc.ca 
that withdrawal of inhaled corticosteroids after at least four months of therapy led to a 1.5-fold increase in clinical exacerbations (RR 1.5; 95\% CI 1.05 to 2.1) compared with those who continued on with steroid therapy. Predictably, health-related quality of life deteriorated at a much faster rate when patients were taken off of inhaled corticosteroids compared with those who remained on these drugs. These beneficial clinical effects were observed in the absence of discernible changes in the rate of descent in $\mathrm{FEV}_{1}$. This suggests that accelerated declines in lung function may be controlled by factors other than airway inflammation. Irrespective of the mechanisms involved, there is compelling evidence to indicate that monotherapy with inhaled corticosteroids improves clinical outcomes in COPD.

\section{THE EFFECTS OF LONG-ACTING BETA $_{2}$-AGONISTS AND INHALED CORTICOSTEROIDS}

Because airflow obstruction is a prominent feature of COPD, long-acting beta ${ }_{2}$-agonists (LABAs) were introduced with the aim of maximizing bronchodilation in these patients. LABAs are potent bronchodilators. They act by stimulating the adenylate cyclase pathways, which, in turn, increase intracellular concentrations of cyclic adenosine monophosphate (20). Although LABAs by themselves have weak anti-inflammatory effects, in vitro studies suggest that they can materially amplify the effects of corticosteroids when given as combination therapy, making it possible to achieve large anti-inflammatory effects even with relatively low doses of corticosteroids (20). For instance, the addition of LABAs to inhaled corticosteroids accelerates translocation of glucocorticoid receptors from the cytoplasm into the nucleus, where they can modify the actions of transcription cofactors, nuclear factor kappa-B and activated protein-1 (21). LABAs also appear to increase the effectiveness of corticosteroids in suppressing expression of adhesion molecules such as intercellular adhesion molecule-1 (20). The bronchodilatory effect of LABAs may also facilitate corticosteroid deposition into areas of the lung, wherein active inflammation is present and prominent. Finally, corticosteroids can potentiate beta $_{2}$ activity by upregulating expression of beta 2 receptors and by preventing receptor uncoupling in response to an inflammatory stimulus (22). Combined with an inhaled corticosteroid, LABAs may, therefore, have additive or even synergistic effects on airway inflammation.

Although there are fewer clinical studies of LABA and inhaled corticosteroid combination therapy than there are for monotherapy with inhaled corticosteroids, the data for combination therapy are, indeed, very impressive. Several high quality, randomized, controlled trials have shown that combination therapy leads to better health-related quality of life over short and long term follow-up periods than inhaled corticosteroids alone (23-26). Overall, patients who received combination therapy with inhaled corticosteroids and LABAs experienced $30 \%$, 20\% and 10\% fewer clinical exacerbations (requiring oral corticosteroids) than those who received placebo, LABA or inhaled corticosteroid monotherapy, respectively (17). Combination therapy improved patients' $\mathrm{FEV}_{1}$ values by over $100 \mathrm{~mL}$ compared with placebo within the first year of therapy. It was more powerful than inhaled corticosteroid or LABA monotherapy in improving trough $\mathrm{FEV}_{1}$ (increase of
$50 \mathrm{~mL} /$ year, 95\% CI $26 \mathrm{~mL} /$ year to $74 \mathrm{~mL} /$ year compared with inhaled corticosteroid monotherapy; increase of $34 \mathrm{~mL} /$ year, 95\% CI $11 \mathrm{~mL} /$ year to $57 \mathrm{~mL} /$ year compared with LABA monotherapy) (17). The beneficial effects of inhaled corticosteroids and LABAs, therefore, appeared to be additive, not synergistic. Although the effect of combination therapy on mortality remains uncertain (pending publication of larger studies powered specifically on mortality), there is a strong suggestion toward decreased mortality with combination products ( $\mathrm{RR}$ versus placebo $0.52 ; 95 \% \mathrm{CI} 0.20$ to 1.34 ). These data are supported by an observational study by Soriano and co-workers (27). In this carefully performed epidemiological study using the United Kingdom General Practice Research Database, an automated database of primary care covering approximately 3.4 million people, the investigators found that COPD patients who received a prescription for an inhaled corticosteroid plus a LABA within 90 days of hospital discharge were $41 \%$ less likely to experience a combined end point of repeat hospitalization for COPD or all-cause mortality. This effect size was larger than that observed with each individual drug alone. Similar data have been reported by the Lovelace Group (28) and by Dutch investigators (28) using a similar experimental design.

\section{CONCLUSIONS}

The totality of evidence strongly indicates that combination therapy with inhaled corticosteroids and LABAs produces beneficial health outcomes in COPD. Combination therapy reduces the rate of exacerbations by nearly one-third and improves trough $\mathrm{FEV}_{1}$ by over $100 \mathrm{~mL}$ compared with placebo within the first year of therapy. There are now emerging data to suggest that combination therapy may have salutary effects on survival. Overall, there is compelling evidence and scientific rationale for using combination therapy in the management of moderate to severe COPD (29).

ACKNOWLEDGEMENTS: Dr Sin is supported by a New Investigator Award from the Canadian Institutes of Health Research and a GSK/St Paul's Hospital Foundation COPD Professorship. Dr Sin has received honoraria for speaking engagements, consultative fees, and research funding from GlaxoSmithKline and AstraZeneca.

\section{REFERENCES}

1. Hogg JC, Senior RM. Chronic obstructive pulmonary disease - part 2: Pathology and biochemistry of emphysema. Thorax 2002;57:830-4.

2. Saetta M, Turato G, Maestrelli P, Mapp CE, Fabbri LM. Cellular and structural bases of chronic obstructive pulmonary disease.

Am J Respir Crit Care Med 2001;163:1304-9.

3. Gompertz S, O’Brien C, Bayley DL, Hill SL, Stockley RA. Changes in bronchial inflammation during acute exacerbations of chronic bronchitis. Eur Respir J 2001;17:1112-9.

4. Aaron SD, Angel JB, Lunau M, et al. Granulocyte inflammatory markers and airway infection during acute exacerbation of chronic obstructive pulmonary disease. Am J Respir Crit Care Med 2001;163:349-55.

5. Roland M, Bhowmik A, Sapsford RJ, et al. Sputum and plasma endothelin-1 levels in exacerbations of chronic obstructive pulmonary disease. Thorax 2001;56:30-5.

6. Singh JM, Palda VA, Stanbrook MB, Chapman KR. Corticosteroid therapy for patients with acute exacerbations of chronic obstructive pulmonary disease: A systematic review. Arch Intern Med 2002;162:2527-36.

7. Barnes PJ. Inhaled glucocorticoids for asthma. N Engl J Med 1995;332:868-75. 
8. Calverley PM. Inhaled corticosteroids are beneficial in chronic obstructive pulmonary disease. Am J Respir Crit Care Med 2000;161:341-2.

9. Barnes PJ. Inhaled corticosteroids are not beneficial in chronic obstructive pulmonary disease. Am J Respir Crit Care Med 2000;161:342-4

10. Barnes PJ, Shapiro SD, Pauwels RA. Chronic obstructive pulmonary disease: Molecular and cellular mechanisms. Eur Respir J 2003;22:672-88.

11. Patel IS, Roberts NJ, Lloyd-Owen SJ, Sapsford RJ, Wedzicha JA. Airway epithelial inflammatory responses and clinical parameters in COPD. Eur Respir J 2003;22:94-9.

12. Balbi B, Majori M, Bertacco S, et al. Inhaled corticosteroids in stable COPD patients: Do they have effects on cells and molecular mediators of airway inflammation? Chest 2000;117:1633-7.

13. Confalonieri M, Mainardi E, Della Porta R, et al. Inhaled corticosteroids reduce neutrophilic bronchial inflammation in patients with chronic obstructive pulmonary disease. Thorax 1998;53:583-5.

14. Hattotuwa KL, Gizycki MJ, Ansari TW, Jeffery PK, Barnes NC. The effects of inhaled fluticasone on airway inflammation in chronic obstructive pulmonary disease: A double-blind, placebo-controlled biopsy study. Am J Respir Crit Care Med 2002;165:1592-6.

15. Sugiura H, Ichinose M, Yamagata S, Koarai A, Shirato K, Hattori T. Correlation between change in pulmonary function and suppression of reactive nitrogen species production following steroid treatment in COPD. Thorax 2003;58:299-305.

16. Alsaeedi A, Sin DD, McAlister FA. The effects of inhaled corticosteroids in chronic obstructive pulmonary disease: A systematic review of randomized placebo-controlled trials. Am J Med 2002;113:59-65.

17. Sin DD, McAlister FA, Man SF, Anthonisen NR. Contemporary management of chronic obstructive pulmonary disease: Scientific review. JAMA 2003;290:2301-12.

18. Spencer S, Calverley PM, Sherwood Burge P, Jones PW; ISOLDE Study Group. Inhaled Steroids in Obstructive Lung Disease. Health status deterioration in patients with chronic obstructive pulmonary disease. Am J Respir Crit Care Med 2001;163:122-8.
19. van der Valk P, Monninkhof E, van der Palen J, Zielhuis G, van Herwaarden C. Effect of discontinuation of inhaled corticosteroids in patients with chronic obstructive pulmonary disease: The COPE study. Am J Respir Crit Care Med 2002;166:1358-63

20. Johnson M, Rennard S. Alternative mechanisms for long-acting beta(2)-adrenergic agonists in COPD. Chest 2001;120:258-70.

21. Roth M, Johnson PR, Rudiger JJ, et al. Interaction between glucocorticoids and beta ${ }_{2}$ agonists on bronchial airway smooth muscle cells through synchronised cellular signalling. Lancet 2002;360:1293-9.

22. Knox AJ. The scientific rationale of combining inhaled glucocorticoids and long acting beta 2 adrenoceptor agonists. Curr Pharm Des 2002;8:1863-9.

23. Mahler DA, Wire P, Horstman D, et al. Effectiveness of fluticasone propionate and salmeterol combination delivered via the Diskus device in the treatment of chronic obstructive pulmonary disease. Am J Respir Crit Care Med 2002;166:1084-91.

24. Calverley PM, Pauwels R, Vestbo J, et al, for the TRISTAN Study Group. Combined salmeterol and fluticasone in the treatment of chronic obstructive pulmonary disease: A randomized controlled trial. Lancet 2003;361:449-56.

25. Szafranski W, Cukier A, Ramirez A, et al. Efficacy and safety of budesonide/formoterol in the management of chronic obstructive pulmonary disease. Eur Respir J 2003;21:74-81.

26. Hanania NA, Darken P, Horstman D, et al. The efficacy and safety of fluticasone propionate $(250 \mathrm{microg}) / \mathrm{salmeterol}(50 \mathrm{microg})$ combined in the Diskus inhaler for the treatment of COPD. Chest 2003;124:834-43.

27. Soriano JB, Vestbo J, Pride NB, Kiri V, Maden C, Maier WC. Survival in COPD patients after regular use of fluticasone propionate and salmeterol in general practice. Eur Respir J 2002;20:819-25.

28. Burney P, Suissa S, Soriano JB, et al. The pharmacoepidemiology of COPD: Recent advances and methodological discussion. Eur Respir J Suppl 2003;43:1S-44S

29. Man SF, McAlister FA, Anthonisen NR, Sin DD. Contemporary management of chronic obstructive pulmonary disease: Clinical applications. JAMA 2003;290:2313-6. 


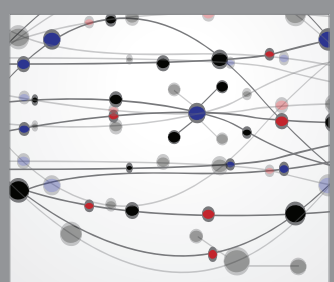

The Scientific World Journal
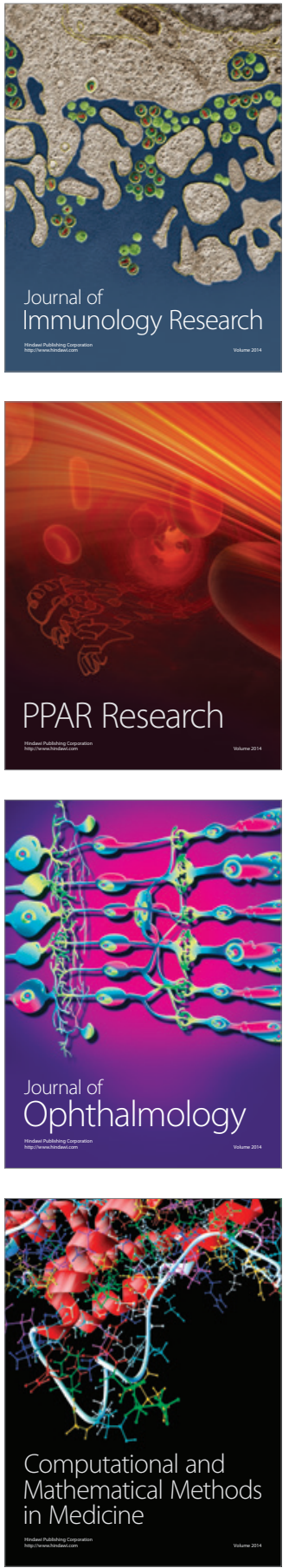

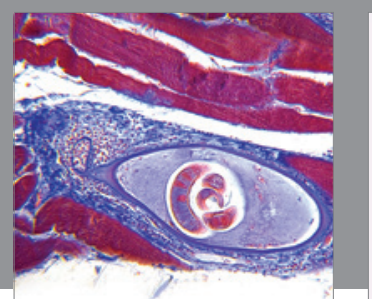

Gastroenterology Research and Practice

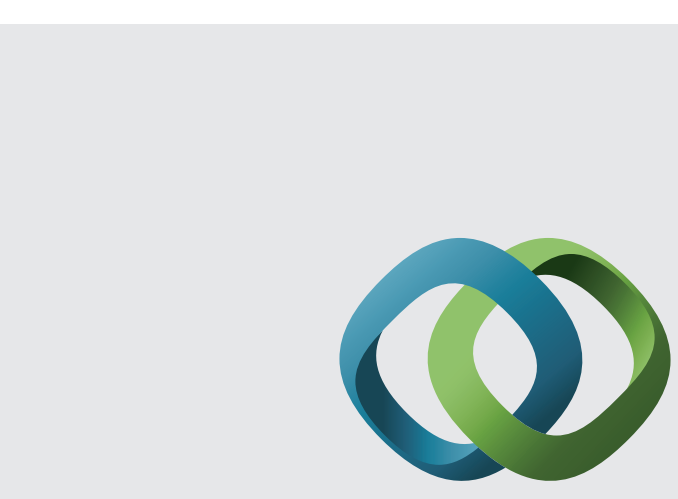

\section{Hindawi}

Submit your manuscripts at

http://www.hindawi.com
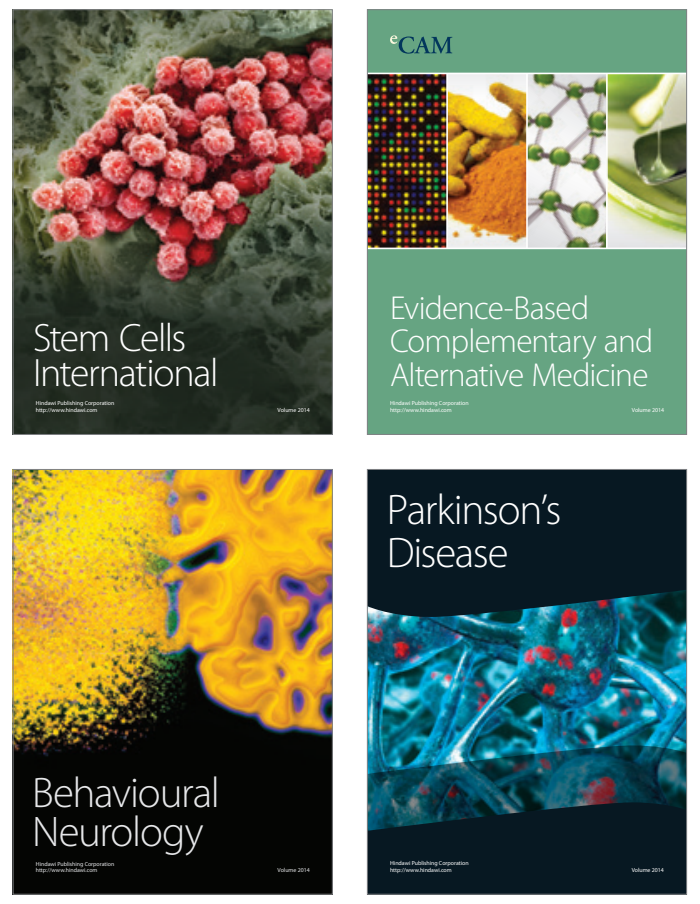
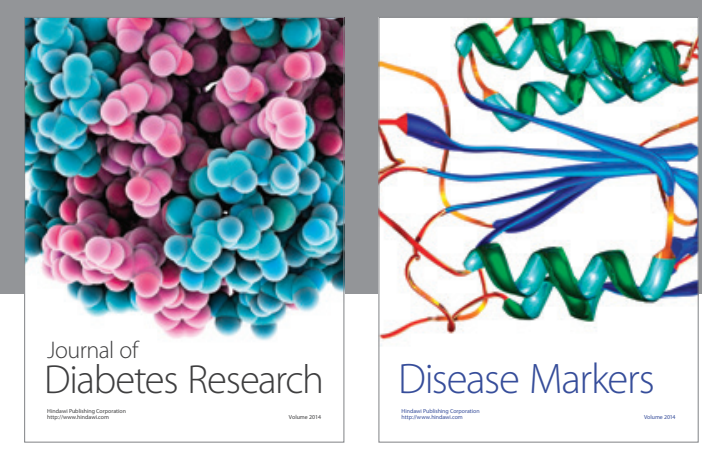

Disease Markers
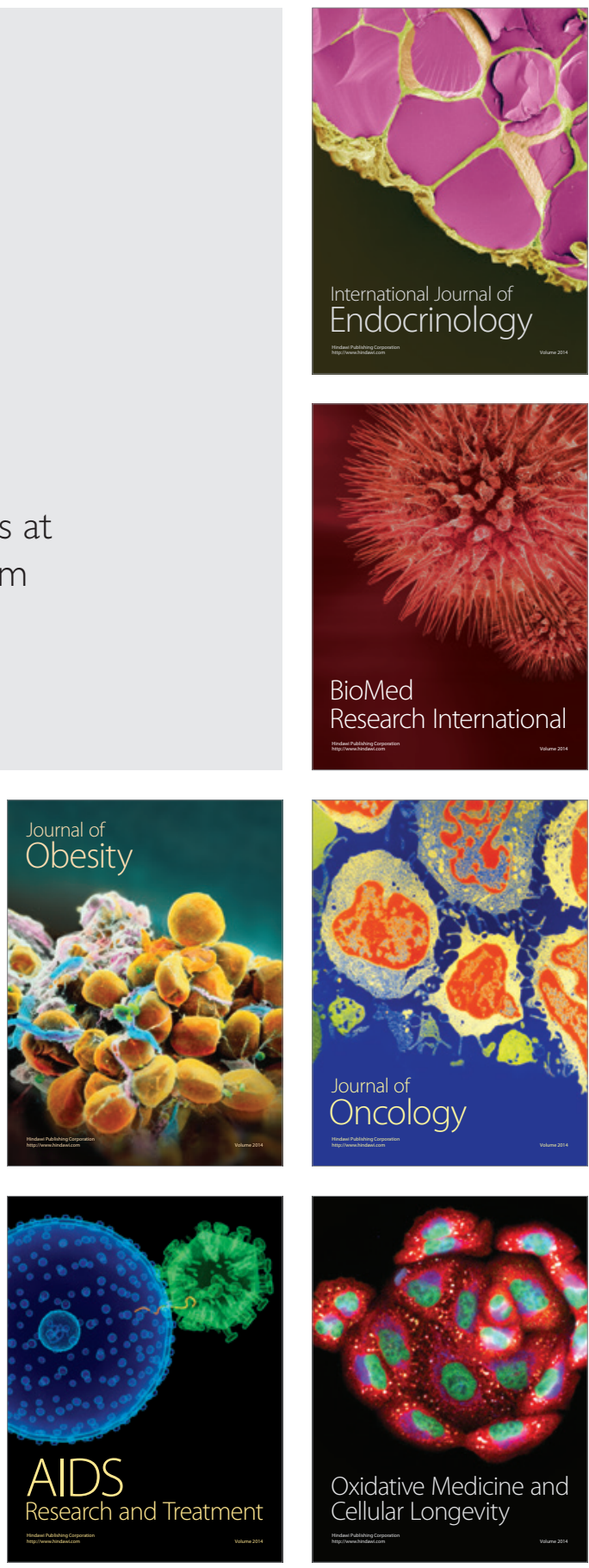